\title{
Rent-seeking in a unionised monopoly ${ }^{\star}$
}

\section{Odd Rune Straume}

Department of Economics, University of Bergen, Fosswinckels gate 6, N-5007 Bergen, Norway (e-mail: odd.straume@econ.uib.no)

Received: June 2000 / accepted: January 2001

\begin{abstract}
A unionised monopoly firm, benefitting from some kind of anticompetitive regulation, and its corresponding trade union have a common interest in spending resources to protect the monopoly rents created by the regulation. In the present paper, a situation in which the unionised monopoly is challenged by a consumer organisation fighting for deregulation is analysed as a standard Tullock rent-seeking contest. With unequal sharing of monopoly rents, the free-riding incentives among the rent-defending players turn out to be overwhelming, in the sense that the unique Nash equilibrium is characterised by zero effort contribution by the player with the lower valuation of the contested prize. This implies that being "strong", in terms of bargaining strength, is not necessarily an advantage for neither player in a unionised monopoly that is threatened by deregulation.
\end{abstract}

Key words: contests, rent-seeking, trade unions

JEL classification: D72, J51, L43

\section{Introduction}

Rent-seeking effort undertaken by firms in order to obtain, or protect, favourable market positions has long been regarded as an integral part of a modern economy. ${ }^{1}$ The literature on rent-seeking activities by firms, which was pioneered by Tullock (1967), Krueger (1974) and Posner (1975), highlights the important insight that the social costs of monopolies created by restrictive regulations are likely to be higher than the "standard" deadweight loss.

* I am indebted to Kai A. Konrad, Steinar Vagstad, Kjell Erik Lommerud, seminar participants at the University of Bergen, and two anonymous referees for their valuable comments.

${ }^{1}$ See Nitzan (1994) for a survey of the theory of rent-seeking. 
In an important paper, Ellingsen (1991) broadens the scope of traditional rentseeking theory by including rent-seeking expenditures by consumers. Indeed, he shows that consumer lobbying against potential and existing monopolies is very likely to be socially beneficial. Other papers analysing consumer participation in rent-seeking contests include Fabella (1993, 1995) and Rama (1997).

In a more general setting, though, it is also natural to include trade unions as independent players in rent-seeking games. Empirically, it is reasonably well documented that imperfect competition in product markets is a major source of rent extraction by unionised labour (see e.g. Rose, 1987; Christophides and Oswald, 1992). Thus, it could be very much in the interest of trade unions to engage in lobbying, or other kinds of actions, directed against regulatory authorities in order to create or preserve various types of market regulations. These kinds of actions are also frequently observed in most industrialised countries. With very few exceptions, though, rent-seeking expenditure by organised labour has not received much attention in the literature.

Following Ellingsen (1991), we can distinguish between two different types of rent-seeking: Rent-seeking by potential producers for a monopoly position, and rent-seeking by an existing monopolist to defend his monopoly position. The effect of unionised labour in rent-seeking contests of the former kind is extensively analysed by Rama (1997), ${ }^{2}$ the main results being that the presence of trade unions makes monopolisation less attractive to firms, and more harmful to consumers. Thus, rent-seeking expenditures by firms are reduced, and the probability of regulation is reduced, compared to the non-union case.

In this paper we concentrate on the latter type of rent-seeking contests. As observed by Ellingsen (1991), in most cases consumers launch their campaigns against existing monopolies. Furthermore, trade unions that are already favoured by existing regulations are probably more likely to play an active part in rentseeking contests.

Our focus is directed towards an existing unionised monopoly that is favoured by some kind of anti-competitive regulation, e.g. protection from international competition. Applying the lottery model of Tullock (1980) we then analyse a rent-seeking contest between the rent-defending players, i.e. the protected firm and its trade union, and an organisation representing consumers' interests. This is a contest between a group of agents (the firm and the union) on one side, and an individual agent (the consumer group) on the other. In this respect it is a special application of a more general group rent-seeking contest (see e.g. Katz, Nitzan and Rosenberg, 1990; Nitzan, 1991; Lee, 1995).

An important feature of this particular contest is the prevalence of free-riding incentives within the rent-defending group. If the rent-defending players win the contest, and regulation is upheld, the "prize" is shared between the firm and the union on the basis of relative bargaining strength in wage negotiations. However, these prize-sharing "rules" are exogenous to the contest itself, and thus, both rentdefending players have strong incentives to free-ride in the contest by leaving

\footnotetext{
${ }^{2}$ Contrary to the present paper, Rama (1997) does not consider trade unions as independent contest participants.
} 
the burden of defending the monopoly to the other player. Indeed, we find that the nature of the non-cooperative Nash equilibrium is crucially dependent upon the rent-defending players' relative valuation of the contested prize. If valuations are unequal, i.e. if monopoly rents are unequally distributed between the firm and the union, the unique Nash equilibrium is characterised by zero contribution of lobbying effort by the player with the lower valuation. If valuations are equal, there is a continuum of equilibria, each in which total rent-defending effort is the same, but relative effort contributions by the firm and the union differs.

The characteristics of the Nash equilibrium, in terms of free-riding, yield some interesting implications with regard to relative bargaining strength. Being "strong" is not necessarily an advantage, for neither the union nor the firm, in a unionised monopoly that is threatened by deregulation. If, say, the union has a relatively low degree of bargaining strength, the workers' share of the monopoly rents is relatively low. This could, however, be more than outweighed, in terms of expected net payoff, by the ability to free-ride on the firm's rent-defending expenditures in the contest.

Having established the Nash equilibrium in the non-cooperative rent-seeking contest, a major part of the paper is devoted to analysing the implications of unionisation with respect to total rent-seeking and social welfare in this particular setting, where the non-union benchmark corresponds to Ellingsen (1991). The presence of a trade union affects the incentives for lobbying expenditures for all contestants, with subsequent implications for total rent-seeking and welfare. An important result is that the presence of a trade union increases the probability of deregulation.

The rest of the paper is organised as follows. In Sect. 2 the basic assumptions of the non-cooperative rent-seeking contest is presented, and the Nash equilibrium is derived. In Sect. 3 the nature of this equilibrium is analysed within the context of a general right-to-manage model, where the sharing of monopoly rents is implicitly determined through wage bargaining. In Sect. 4 we consider the possibility of rent-defending cooperation between the firm and the union. Section 5 offers some concluding remarks.

\section{A Tullock rent-seeking contest}

Consider a regulated unionised monopoly that comes under pressure from a consumer organisation that is fighting for deregulation. The type of regulation could typically be protection from international competition. This is a case in which both the monopolised firm and its trade union have a common interest in preserving the protective regulation.

We assume that whether or not regulation is upheld is dependent on the amount of lobbying activity exercised by the players towards the regulatory authorities. The exact specification of the rules of the contest is that of a Tullock (1980) game, where the outcome of the contest is the assignment to each player 
of a probability that he wins the prize. ${ }^{3}$ The probability of winning the contest is determined by relative rent-seeking effort. Using a standard Tullock probability function, ${ }^{4}$ the probability that regulation is preserved, $\mu$, is given by

$$
\mu=\frac{x+z}{x+z+y}
$$

where $x$ and $z$ are effort contributions by the firm and the union, respectively, whereas $y$ is the effort of the consumers' association. With this particular contest success function we assume that effort contribution by either of the rent-defending players is equally effective.

A special characteristic of this particular contest is that the players have different valuations of the contested prize. The monopoly firm and its trade union are both defending the opportunity to extract some monopoly rents from the market. If regulation is upheld, these rents are shared between the rent-defending players according to their relative bargaining strength. We denote monopoly profits by $t$, whereas union rents are denoted by $r$.

The consumers, on the other hand, are fighting for a competitive price level in the market. If the consumer organisation wins the contest, and the monopoly is deregulated, its valuation is given by the full monopoly rents $(t+r)$, in addition to the efficiency loss from monopolisation, denoted by $h .^{5}$

Assuming risk-neutrality, expected net payoff for the firm and the union, respectively, are given by

$$
\begin{aligned}
& E\left(\pi_{f}\right)=\mu t-x \\
& E\left(\pi_{u}\right)=\mu r-z
\end{aligned}
$$

whereas expected net payoff for the consumer group is given by

$$
E\left(\pi_{c}\right)=(1-\mu)(t+r+h)-y
$$

\footnotetext{
${ }^{3}$ This is an imperfectly discriminatory contest, in which the highest bid does not win with certainty. Compared to the other standard alternative from the rent-seeking literature (the perfectly discriminatory contest), we believe the Tullock lottery model to be a more realistic description of the impact of lobbying expenditures on political decisions.

${ }^{4}$ Tullock (1980) proposes a contest success function of a more general form, where an agent's chance of success in a contest is given by

$$
p_{i}\left(x_{i}\right)=\frac{x_{i}^{a}}{\sum_{j=1}^{n} x_{j}^{a}}
$$

(see Skaperdas (1996) for an axiomatisation). However, since there are asymmetric valuations of the contested prize in our model, we choose $a=1$ for greater analytical tractability. Regarding the generality of this specification, the properties of the Nash equilibrium (reported in Proposition 1) are qualitatively dependent on $a$ being sufficiently large.

${ }^{5}$ Here we make two implicit assumptions. Firstly, we assume that deregulation yields a competitive market price. Secondly, we assume, as Ellingsen (1991) does, that all consumers are organised. Rama (1997) makes the, perhaps more realistic, assumption that a single consumer association is representing a fraction $c \in[0,1]$ of the consumers. For simplicity, we follow Ellingsen and set $c=1$.
} 


\subsection{Equilibrium}

The solution concept is that of Nash equilibrium. Each player chooses his level of effort by maximising expected net payoff. For simplicity, we assume that the players are not wealth constrained. The non-cooperative Nash equilibrium outcome is given by the solution to the players' simultaneous concave programming problems, given by the following:

$$
\begin{array}{lll}
\max _{x} \mu t-x & \text { s.t. } & x \geq 0 \\
\max _{z} \mu r-z & \text { s.t. } & z \geq 0 \\
\max _{y}(1-\mu)(t+r+h)-y & \text { s.t. } & y \geq 0
\end{array}
$$

From the solution to this problem, the following proposition is derived:

Proposition 1 (i) If $t \neq r$ there is a unique equilibrium, characterised by zero effort contribution from the rent-defending player with the lower valuation of the prize. (ii) If $t=r$ there is a continuum of equilibria, each in which the sum of rent-defending effort is constant, but the division of effort between the firm and the trade union differs.

A proof is provided in Appendix A.

If the firm and the union value the right to extract monopoly rents differently, Proposition 1 proves the existence of a unique Nash equilibrium in which the rent-defending player with the higher valuation contributes all the contest effort, whereas the other player is a free rider. Thus, there are both benefits and costs, in terms of net expected payoff, by being the player that captures the larger share of the rents.

This result is clearly related to the large literature on private provision of public goods, which was pioneered by Olson (1965). In our setting, rent-defending effort can be viewed as a local public good that is provided by voluntary contributions from the firm and the trade union. The phenomenon of free-riding incentives in public good provision of this kind has been extensively analysed (see e.g. McGuire, 1974; Chamberlin, 1976; Cornes and Sandler, 1985). However, most of the analysis have used the assumption of identical individual preferences for the public good. A notable exception is Bergstrom et al. (1986), who point out that even very small changes in preferences can lead to a large change in the structure of the equilibrium, with respect to free-riding. In a specific example with quasilinear utility, they find that the agent with the strongest preference for the public good makes all the contribution, while the other agents are free riders. This is a result similar to Proposition 1, considering that the rent-defending players' valuation of the prize is a measure of their preferences for lobbying effort. 


\section{Union-firm bargaining}

Rent-sharing is assumed to be determined through bargaining between the firm and the union. The literature is dominated by two classes of trade union models, ${ }^{6}$ which are commonly referred to as right-to-manage (with the monopoly union model as a special case) and efficient bargaining. In right-to-manage models, the union and the firm bargain over the wage level, whereas employment is unilaterally set by the firm. Efficient bargaining, on the other hand, depicts the case in which both wages and employment are subject to bargaining. In any case, rent-sharing between the rent-defending players are determined by a number of factors (e.g. relative bargaining strength, the mode of bargaining, product market conditions) that are exogenous to the contest itself.

In the following analysis we will apply a standard right-to-manage model in which monopoly rents are implicitly shared between the union and the firm through wage bargaining. This approach corresponds well with the observation that most collective bargaining contracts seem to leave firms with full discretion over the level of employment.

The outcome of wage bargaining is determined by the relative bargaining strength of the negotiating players. Let $\alpha \in(0,1)$ denote the relative bargaining strength of the trade union. We then make the assumption that the size of $\alpha$ uniquely determines the equilibrium levels of profits, union rents and consumers' surplus, and further, that $t, r$ and $h$ can be defined as continuous, differentiable functions of $\alpha$.

Without making any specific assumptions about product market demand, except that the demand curve is downward sloping, or the bargaining game itself, we can make the following general assumptions about $r(\cdot), t(\cdot)$ and $h(\cdot)$ :

$$
\begin{gathered}
r(0)=0, \quad t(1)>0 \\
r^{\prime}(\alpha)>0, \quad t^{\prime}(\alpha)<0, \quad h^{\prime}(\alpha)>0 \\
r^{\prime}(\alpha)+t^{\prime}(\alpha)<0, \quad r^{\prime}(\alpha)+t^{\prime}(\alpha)+h^{\prime}(\alpha)>0
\end{gathered}
$$

Additionally, we assume that $t(1)<r(1)$, implying the existence of a value $\widehat{\alpha}<1$, so that

$$
r(\widehat{\alpha})=t(\widehat{\alpha})
$$

These assumptions incorporate the features of the right-to-manage model. The presence of a trade union implies an additional inefficiency in rent extraction. If the union is able to increase wages through bargaining, the firm will optimally respond by passing some of the cost increase on to consumers in the form of a higher product price. Thus, increased union strength in wage bargaining implies that the efficiency loss increases, while consumers' surplus is reduced.

\footnotetext{
${ }^{6}$ See Oswald (1985) for an overview.
} 
As stated in Proposition 1, the Nash equilibrium of the rent-seeking contest is characterised by a "switching" property, resulting in zero effort contribution from the rent-defending player with the lower valuation of the prize. We are now in a position to explore the implications of this property in the context of relative bargaining strength.

For notational convenience we define the consumers' valuation of the contested prize as

$$
s(\alpha)=t(\alpha)+r(\alpha)+h(\alpha)
$$

Inserting the equilibrium levels of contest effort into (1), (2) and (3), we find expected net payoff for the firm and the union to be given by ${ }^{7}$

$$
\begin{gathered}
E\left[\pi_{f}^{*}(\alpha)\right]=\left\{\begin{array}{lll}
\frac{t(\alpha)^{3}}{[s(\alpha)+t(\alpha)]^{2}} & \text { if } & \alpha<\widehat{\alpha} \\
\frac{r(\alpha) t(\alpha)}{[s(\alpha)+r(\alpha)]} & \text { if } & \alpha>\widehat{\alpha}
\end{array}\right. \\
E\left[\pi_{u}^{*}(\alpha)\right]=\left\{\begin{array}{lll}
\frac{r(\alpha) t(\alpha)}{[s(\alpha)+t(\alpha)]} & \text { if } & \alpha<\widehat{\alpha} \\
\frac{r(\alpha)^{3}}{[s(\alpha)+r(\alpha)]^{2}} & \text { if } & \alpha>\widehat{\alpha}
\end{array}\right.
\end{gathered}
$$

Proposition $2 \exists \delta \in(0,1)$ such that, for any $\alpha^{\prime} \in(\widehat{\alpha}-\delta, \widehat{\alpha})$ and $\alpha^{\prime \prime} \in(\widehat{\alpha}, \widehat{\alpha}+\delta)$, $E\left[\pi_{f}^{*}\left(\alpha^{\prime}\right)\right]<E\left[\pi_{f}^{*}\left(\alpha^{\prime \prime}\right)\right]$ and $E\left[\pi_{u}^{*}\left(\alpha^{\prime}\right)\right]>E\left[\pi_{u}^{*}\left(\alpha^{\prime \prime}\right)\right]$.

Proof. Due to continuity of $r(\cdot)$ and $t(\cdot)$ it is sufficient to show that

$$
\lim _{\alpha \rightarrow \widehat{\alpha}^{+}} E\left[\pi_{f}^{*}(\alpha)\right]>\lim _{\alpha \rightarrow \widehat{\alpha}^{-}} E\left[\pi_{f}^{*}(\alpha)\right]
$$

and

$$
\lim _{\alpha \rightarrow \widehat{\alpha}^{+}} E\left[\pi_{u}^{*}(\alpha)\right]<\lim _{\alpha \rightarrow \widehat{\alpha}^{-}} E\left[\pi_{u}^{*}(\alpha)\right]
$$

Using (10) and (11) we find that both conditions are satisfied if $\frac{[t(\widehat{\alpha})]^{2}}{[s(\widehat{\alpha})+t(\widehat{\alpha})]}>$ $\frac{[t(\widehat{\alpha})]^{3}}{[s(\widehat{\alpha})+t(\widehat{\alpha})]^{2}}$. A simple rearrangement reduces this condition to

$$
[t(\widehat{\alpha})]^{2} s(\widehat{\alpha})[s(\widehat{\alpha})+t(\widehat{\alpha})]>0
$$

which is unambiguously true.

\footnotetext{
${ }^{7}$ For space-saving purposes, equilibrium values for $\alpha=\widehat{\alpha}$ are dropped from the mathematical expressions throughout the paper. This simplification does not influence the analysis in any way.
} 
Proposition 2 implies that it is not necessarily an advantage, for neither player, to have a high degree of bargaining strength in a unionised monopoly that is threatened by deregulation. Put differently, it is possible to be "too strong" in this setting. This result illustrates the conflict between ex ante and ex post interests for the rent-defending players. Ex ante, being able to free-ride in the rent-seeking contest is the privilege of the weaker player, whereas ex post, being the weaker player is obviously a disadvantage in wage bargaining. Thus, since the rent-defending players' ex post payoffs are monotonic in $\alpha$, there exists a neighbourhood of $\widehat{\alpha}$ in which both the union and the firm ex ante would prefer to be the weaker player, because the rent-defending outlays more than outweigh the benefits of gaining a larger share of the rents if regulation is preserved.

To offer a further characterisation of $\delta$, which could potentially be large, some additional assumptions about the bargaining game and the product demand function are necessary. Applying the generalised Nash bargaining model with linear demand, the result in Proposition 2 is illustrated in Fig. 1. ${ }^{8}$

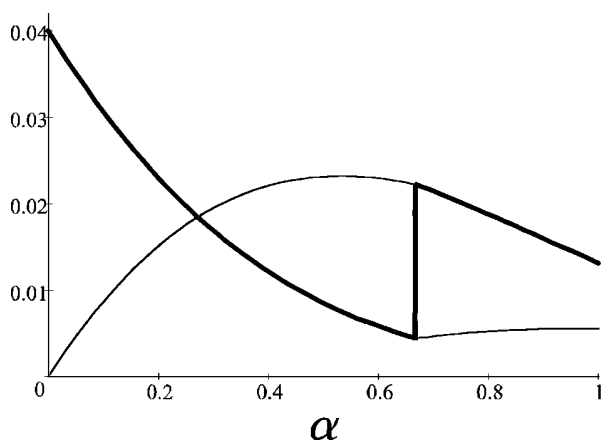

Fig. 1. Net expected payoff for the firm (thick curve) and the union (thin curve) with linear demand

With this particular specification of the model, the "switching point" is given by $\widehat{\alpha}=\frac{2}{3}$. An interesting observation is the non-monotonicity of the trade union's ex ante payoff for $\alpha<\widehat{\alpha}$. Even when the union is free-riding in the contest, expected net payoff for the union is decreasing in its own relative bargaining strength when $\alpha$ approaches $\widehat{\alpha}$. This is caused by rapidly decreasing incentives for the firm to contribute contest effort, which results in a reduced win probability for the rent-defending players, and this is not fully compensated for, in terms of expected union utility, by a larger share of the rents if the contest is won.

For the remainder of this section, the analysis will concentrate on the impact of unionisation on rent-seeking and social welfare. In the general model, $\alpha=0$ represents the non-union case, whereas $\alpha>0$ represents the case of a unionised monopoly.

\footnotetext{
${ }^{8}$ See Appendix B for an explicit derivation of the equilibrium.
} 


\subsection{Rent-seeking}

The equilibrium levels of rent-seeking effort for the contestants are given by

$$
\begin{aligned}
& x^{*}(\alpha)=\left\{\begin{array}{ccc}
\frac{[t(\alpha)]^{2} s(\alpha)}{[s(\alpha)+t(\alpha)]^{2}} & \text { if } & \alpha<\widehat{\alpha} \\
0 & \text { if } & \alpha>\widehat{\alpha}
\end{array}\right. \\
& z^{*}(\alpha)=\left\{\begin{array}{ccc}
0 & \text { if } & \alpha<\widehat{\alpha} \\
\frac{[r(\alpha)]^{2} s(\alpha)}{[s(\alpha)+r(\alpha)]^{2}} & \text { if } & \alpha>\widehat{\alpha}
\end{array}\right. \\
& y^{*}(\alpha)=\left\{\begin{array}{lll}
\frac{[s(\alpha)]^{2} t(\alpha)}{[s(\alpha)+t(\alpha)]^{2}} & \text { if } & \alpha<\widehat{\alpha} \\
\frac{[s(\alpha)]^{2} r(\alpha)}{[s(\alpha)+r(\alpha)]^{2}} & \text { if } & \alpha>\widehat{\alpha}
\end{array}\right.
\end{aligned}
$$

Summing over individual contributions, we get the total rent-seeking outlays in equilibrium, $T R^{*}$ :

$$
T R^{*}(\alpha)=\left\{\begin{array}{lll}
\frac{s(\alpha) t(\alpha)}{s(\alpha)+t(\alpha)} & \text { if } & \alpha<\widehat{\alpha} \\
\frac{s(\alpha) r(\alpha)}{s(\alpha)+r(\alpha)} & \text { if } & \alpha>\widehat{\alpha}
\end{array}\right.
$$

By comparing the equilibrium values for $\alpha=0$ and $\alpha>0$, we are able to establish the effect of unionisation on rent-seeking expenditures.

Proposition 3 Unionisation implies that (i) less rent-seeking effort is exerted to defend the monopoly, and (ii) total rent-seeking effort is also reduced, unless the reduction of consumers' surplus is large relative to the reduction of monopoly rents for the active rent-defending contestant.

Proof. (i) To simplify notation, let $t(\alpha)=t$ and $t(0)=\bar{t}$, with similar notation for the other variables. Consider the case of $\alpha<\widehat{\alpha}$. Using (12), and the definition of $s$, we find, through some tedious rearranging, that $x^{*}(0)>x^{*}(\alpha)$ if $\left(\bar{t}^{3} h^{2}-t^{2}(t+r) \bar{h}^{2}\right)+h \bar{h}\left(h \bar{t}^{2}-\bar{h} t^{2}\right)+r \bar{s} \bar{t}^{2}(2 h+r)+4 t \bar{t} \bar{s} s(\bar{t}-t)>0$. Since $\bar{t}>(t+r)$ and $h>\bar{h}$, this is unambiguously true. For $\alpha>\widehat{\alpha}$ we can exploit the symmetric nature of the equilibrium. Replacing $t$ with $r$ in the above inequality yields the condition for $x^{*}(0)>z^{*}(\alpha)$, which is also unambiguously true.

(ii) Using (15) we find that, for $\alpha<\widehat{\alpha}, T R^{*}(0)>T R^{*}(\alpha)$ if $s \bar{s}(\bar{t}-t)+$ $\bar{t} t(\bar{s}-s)>0$. For $\alpha>\widehat{\alpha}$, we find that $T R^{*}(0)>T R^{*}(\alpha)$ if $s \bar{s}(\bar{t}-r)+$ $\bar{t} r(\bar{s}-s)>0$. We see that both conditions hold unless $|\bar{s}-s|$, which is a measure of the reduction in consumers' surplus, is large relative to the reduction of rents, $(\bar{t}-t)$ or $(\bar{t}-r)$, for the active rent-defending contestant. 
The first part of Proposition 3 is intuitively straightforward. The presence of a trade union means that the active rent-defending contestant has a lower valuation of the prize. Consequently, the incentives for spending resources to defend the monopoly are unambiguously reduced.

In contrast, the presence of a union implies that consumers are facing two opposite incentives for effort contribution in the contest. On the one hand, a lower level of effort by the rent-defending player allows the consumer group also to reduce its effort. On the other hand, the extra inefficiency caused by the trade union increases the consumers' valuation of the contested prize, implying a higher incentive to exert effort. The relative magnitude of these two incentives is determined by the relative change in valuations for the contestants, compared with the non-union case. If the reduction of consumers' surplus, which is equivalent to the increase in valuation for the consumers, is large relative to the reduction in valuation for the active rent-defending contestant, the second incentive is dominating, and the consumer group will spend more resources on rent-seeking. If this effect is sufficiently strong, the incentives for the consumers to increase rent-seeking effort could possibly outweigh the reduction in contest effort for the rent-defending player, causing total rent-seeking to increase.

The actual size of the relative change in valuations depends of course on the characteristics of the product demand function. We can, however, make two different observations about the relationship between total rent-seeking outlays and relative bargaining strength. For $\alpha>\widehat{\alpha}$, total rent-seeking is always increasing in the union's relative bargaining strength. ${ }^{9}$ This result is intuitively easy to explain. Since the union is the active rent-defending contestant for $\alpha>\widehat{\alpha}$, it follows that both contestants' valuation of the prize is increasing in $\alpha$. Thus, a higher value of $\alpha$ within this regime means that both the union and the consumer group have an incentive to spend more resources on rent-seeking. For $\alpha<\widehat{\alpha}$, on the other hand, it will generally be the case that a sufficient degree of convexity in demand is required for total rent-seeking to increase in the union's relative bargaining strength. ${ }^{10}$

The effects of unionisation and relative bargaining strength on total rentseeking is illustrated in Fig. 2 for the case of linear demand. For this specific case we see that the presence of a trade union always reduces total rent-seeking.

\footnotetext{
${ }^{9}$ From (15) it is easily confirmed that $\frac{\partial T R}{\partial \alpha}>0$ for $\alpha>\widehat{\alpha}$.

10 The extent to which the reduction in consumers' surplus is large relative to the reduction in firm profits as $\alpha$ increases, depends on to which extent the firm is able to shift an increase in wages on to the consumers in the form of a higher product price. Let product demand be given by the function $D(p)$, and consider the following standard monopoly problem:
}

$$
\max _{p} \pi=(p-w) D(p)
$$

Differentiating the first order condition of this problem with respect to $w$ yields

$$
\frac{d p}{d w}=\frac{D^{\prime}(p)}{2 D^{\prime}(p)+(p-w) D^{\prime \prime}(p)}
$$

We see that the increase in the product price as a response to a marginal increase in wages is higher the more convex is $D(p)$. 


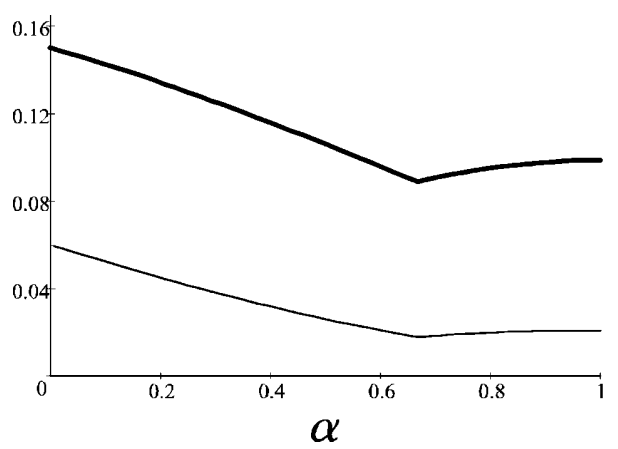

Fig. 2. Rent-defending outlays (thin curve) and total rent-seeking (thick curve) with linear demand

\subsection{Probability of deregulation}

Since unionisation affects rent-seeking incentives, the probability of deregulation will also be affected. Inserting the equilibrium rent-seeking expenditures, (12)(14), into (1), the equilibrium probability that regulation is preserved is found to be:

$$
\mu^{*}(\alpha)=\left\{\begin{array}{lll}
\frac{t(\alpha)}{s(\alpha)+t(\alpha)} & \text { if } & \alpha<\widehat{\alpha} \\
\frac{r(\alpha)}{s(\alpha)+r(\alpha)} & \text { if } & \alpha>\widehat{\alpha}
\end{array}\right.
$$

From (16) the following proposition is established:

Proposition 4 Unionisation implies that the probability of deregulation increases.

Proof. For $\alpha<\widehat{\alpha}, \mu^{*}(0)>\mu^{*}(\alpha)$ if $\frac{t(0)}{s(0)+t(0)}>\frac{t(\alpha)}{s(\alpha)+t(\alpha)}$. This condition reduces to $t(0) s(\alpha)>t(\alpha) s(0)$. For $\alpha>\widehat{\alpha}, \mu^{*}(0)>\mu^{*}(\alpha)$ if $\frac{t(0)}{s(0)+t(0)}>\frac{r(\alpha)}{s(\alpha)+r(\alpha)}$. This condition reduces to $t(0) s(\alpha)>r(\alpha) s(0)$. Since $t(0)>t(\alpha), t(0)>r(\alpha)$ and $s(\alpha)>s(0)$, both conditions hold unambiguously.

The intuition of this result is fairly straightforward. The presence of a trade union implies that the consumer lobby puts a relatively higher value on the contested prize than do the active rent-defending player. This will shift the incentives for rent-seeking, so that a larger share of total rent-seeking is carried out by consumers. Consequently, the probability of deregulation will increase.

\subsection{Welfare}

Standard models of trade unions tend to emphasise the efficiency loss caused by unionisation. Taking rent-seeking incentives into consideration, the welfare effects of unionisation might not be so clear-cut, though. An appropriate measure of social welfare in this context must somehow incorporate the fact that the presence of a trade union will affect the probability of deregulation. 
It seems natural to use the sum of expected payoffs for the different players as a (partial) measure of expected social welfare. We let consumers' surplus in the monopoly case be denoted by $C S(\alpha)$. Denoting consumers' surplus in the case of a competitive market by $\overline{C S}$, we have that expected welfare is given by

$$
E[W(\alpha)]=\mu(\alpha)[C S(\alpha)+t(\alpha)+r(\alpha)]+[1-\mu(\alpha)] \overline{C S}-T R(\alpha)
$$

where

$$
\overline{C S}=C S(\alpha)+t(\alpha)+r(\alpha)+h(\alpha)
$$

A simple rearrangement yields

$$
E[W(\alpha)]=C S(\alpha)+[t(\alpha)+r(\alpha)]+[1-\mu(\alpha)] h(\alpha)-T R(\alpha)
$$

The "standard" measure of social welfare is given by the first two terms on the right hand side, which denote consumers' surplus and total monopoly rents, respectively. Due to the inefficiency in rent extraction caused by the trade union, both these terms are decreasing in $\alpha$. The third term captures how the presence of a trade union affects the probability of deregulation. With probability $(1-\mu)$ the monopoly is deregulated, and social welfare is increased by $h$. Since $\mu$ is decreasing in $\alpha$, whereas $h$ is increasing in the union's relative bargaining strength, we see that unionisation has a positive effect on expected social welfare in this respect. Although the presence of a union creates an extra inefficiency by inducing a higher product price, it also affects rent-seeking incentives in a way that increases the probability of deregulation. The inclusion of the last term in the welfare function implies that rent-seeking as such is perceived as socially wasteful. From Proposition 3 we know that the effect of unionisation on total rent-seeking is ambiguous, but most likely negative.

Not surprisingly, given the above analysis, the total effect of unionisation on social welfare is dependent on the characteristics of product demand, and thus ambiguous. Using the assumption of linear demand, though, we find that the presence of a trade union always leads to an increase in expected social welfare in this setting.

\section{Cooperative rent-defending}

Due to the problem of free-riding in the non-cooperative contest, it would perhaps be natural to assume that the rent-defending players could do better by forming a cooperative agreement. Let us assume that the total amount of rent-defending effort is jointly determined by the firm and its trade union. In this case the pro-regulation coalition maximises

$$
E\left(\pi_{f}+\pi_{u}\right)=\mu(t+r)-x_{c}
$$

where $x_{c}$ is the joint amount of rent-defending outlays. As before, the consumer group chooses the level of contest effort that maximises (4). 
Solving these two optimisation problems, we find the equilibrium rent-seeking outlays in the cooperative version of the model to be

$$
\begin{gathered}
x_{c}(\alpha)=\frac{[s(\alpha)-h(\alpha)]^{2} s(\alpha)}{[2 s(\alpha)-h(\alpha)]^{2}} \\
y_{c}(\alpha)=\frac{[s(\alpha)]^{2}[s(\alpha)-h(\alpha)]}{[2 s(\alpha)-h(\alpha)]^{2}}
\end{gathered}
$$

Under rent-defending cooperation, the efficiency loss, $h$, is a measure of the asymmetry between the contestants' valuation of the prize. From (19) and (20) it is easily verified that the higher is $h$, the larger share of total rent-seeking is undertaken by the consumers.

Inserting (19)-(20) into (18), we find expected total payoff to the rentdefending coalition to be given by

$$
E\left(\pi_{f}+\pi_{u}\right)=\frac{[s(\alpha)-h(\alpha)]^{3}}{[2 s(\alpha)-h(\alpha)]^{2}}
$$

Proposition 5 Cooperation between the rent-defending players is not jointly profitable if ( $i$ ) the efficiency loss is sufficiently high, or (ii) the union's relative bargaining strength is sufficiently low.

Proof. Cooperation is not jointly profitable if $E\left(\pi_{f}+\pi_{u}\right)<E\left(\pi_{f}^{*}\right)+E\left(\pi_{u}^{*}\right)$. Using (10), (11) and (21) we find that this condition reduces to

$$
h[t(2 t+h)+r(t-r)]-r(t+r)^{2}>0 \quad \text { if } \quad \alpha<\widehat{\alpha}
$$

and

$$
h[r(2 r+h)+t(r-t)]-t(t+r)^{2}>0 \quad \text { if } \quad \alpha>\widehat{\alpha}
$$

Since the first term in both (22) and (23) is positive, we see that both conditions hold if $h$ is sufficiently high. Furthermore, since $r(0)=0$ we see that condition (23) holds unambiguously if $\alpha=0$. Due to continuity of $r(\cdot)$ the condition must also hold for some small values of $\alpha$.

Whether or not it is jointly profitable for the rent-defending players to coordinate their actions in the lobbying game, is crucially dependent on the strategic response from the opponent. If the increase in lobbying effort from the consumers more than outweigh the benefit of internalising the free-rider effect, the firm and the union are jointly worse off by cooperating in the contest. Proposition 5 indicates that this result is most likely to appear if the players' relative bargaining strengths are sufficiently unequal.

This result is highly related to the well-known analysis of strategic behaviour in contests by Dixit (1987). He shows that in a contest of this kind, with asymmetric valuations of the prize, the player with the lower valuation (the "underdog") has an incentive to pre-commit to a lower level of contest effort. 
In this particular setting the rent-defending coalition is the "underdog". Thus, free-riding may actually be beneficial for the coalition as a whole, since total rent-defending outlays are reduced, compared to the cooperative alternative.

Whether or not cooperation is jointly profitable depends on the equilibrium level of rent-defending lobbying in the non-cooperative game compared to the Stackelberg level of lobbying. The optimal level of effort reduction if the coalition was able to act as a Stackelberg leader is dependent on the degree of asymmetry in the contest. If the degree of asymmetry is sufficiently high, i.e. if $h$ is sufficiently high, the effort level in the free-riding equilibrium is either above or sufficiently close to the Stackelberg level of effort, making the cooperative alternative jointly unprofitable. $^{11}$

Considering the second part of Proposition 5, the relative reduction of effort obtained by not cooperating, is determined by the difference between $(t+r)$ and the valuation by the active rent-defending contestant in the non-cooperative equilibrium. If $\alpha$ is small, then $r$ is small and $(t+r)$ is close to $t$, which is the firm's valuation of the prize. Thus, if $\alpha$ is close to 0 , non-cooperation amounts to a marginal reduction of rent-defending effort, compared to the cooperative alternative, and this is obviously jointly profitable, irrespective of $h$.

Once again, if we assume product demand to be linear we find that rentdefending cooperation is never profitable.

\section{Concluding remarks}

By including trade unions as independent players in a Tullock model of rentseeking, we are able to shed some new light on the rent-seeking theory, as well as the theory on trade unionism. While traditional theories of trade unions tend to focus on the conflicting interests of union workers and their employers, the common interest of firms benefitting from anti-competitive regulation and their corresponding trade unions becomes very obvious in a context of rent-seeking.

In the present model the monopoly firm and its union have an ex ante common interest in preserving the monopoly position, whereas ex post the usual conflict of interests regarding the division of monopoly rents resurfaces. An interesting feature of the non-cooperative Nash equilibrium is the fact that the "weaker" player in the ex post bargaining game is able to take advantage of the common interest of the rent-defending players in the contest by being a free-rider. Thus, being "strong", in terms of relative bargaining strength, need not be an advan-

11 The Stackelberg level of effort is given by

$$
x_{s}=\frac{1}{4} \frac{(s-h)^{2}}{s}
$$

Using (12) and (13) it is easily shown that

$$
\frac{\partial}{\partial h}\left(\left(x^{*}+z^{*}\right)-x_{s}\right)>0
$$


tage, in terms of expected net payoff, when a unionised monopoly is facing the possibility of deregulation.

The model could be extended in numerous ways. An obvious extension would be to allow for different rent-sharing procedures in the unionised monopoly, e.g. efficient bargaining. This would not change the nature of the non-cooperative equilibrium, but it would make some of the other results more clear-cut. For instance, with efficient bargaining, the presence of a trade union will always reduce total rent-seeking and increase ex ante social welfare. On the other hand, rent-defending cooperation could be more profitable.

Finally, another interesting extension would be to introduce some bias in the contest success function. In the present model, it is implicitly assumed that the total effect of rent-defending effort is independent of the relative contributions made by the rent-defending players. It could easily be the case, though, that the government is more receptive to lobbying by one or the other of the rentdefending players, and in this case, contest effort made by different players should be weighted differently in the contest success function.

\section{A. Proof of Proposition 1}

We start by proving part (ii) of the proposition. The Lagrangian functions are given by

$$
\begin{gathered}
L_{x}=\left(\frac{x+z}{x+z+y}\right) t-x+\lambda_{x} x \\
L_{z}=\left(\frac{x+z}{x+z+y}\right) r-z+\lambda_{z} z \\
L_{y}=\left(\frac{y}{x+z+y}\right)(t+r+h)-y+\lambda_{y} y
\end{gathered}
$$

Assume that effort contributions from all players are strictly positive. From the standard Kuhn-Tucker conditions, this implies $\lambda_{x}=\lambda_{z}=\lambda_{y}=0$. Using the first-order conditions, we have that

$$
\begin{gathered}
x=\sqrt{y t}-y-z \\
z=\sqrt{y r}-y-x \\
y=\sqrt{(x+z)(t+r+h)}-x-z
\end{gathered}
$$

Now assume that the firm contributes an amount of effort equal to $b>0$. Inserting $x=b$ into (A.5) and (A.6), and solving for $z$ and $y$, we find the 
optimal responses for the union and the consumer group, respectively, to an effort contribution $x=b$ by the firm:

$$
\begin{gathered}
z^{*}=\frac{r^{2}(t+r+h)}{(2 r+t+h)^{2}}-b \\
y^{*}=\frac{r(t+r+h)^{2}}{(2 r+t+h)^{2}}
\end{gathered}
$$

Inserting $z^{*}$ and $y^{*}$ into (A.4) yields

$$
x^{*}=\frac{b(2 r+t+h)+(\sqrt{r} \sqrt{t}-r)(t+r+h)}{2 r+t+h}
$$

From (A.9) we see that $x^{*}=b$ iff $r=t$. Thus, in equilibrium there are positive effort contributions from both the union and the firm only if their valuation of the prize is identical.

Obviously, $y^{*}=0$ or $x^{*}=z^{*}=0$ cannot be part of a Nash equilibrium. This leaves us with two possible corner solutions:

1) Assume that $x^{*}=0$, whereas $z^{*}>0$ and $y^{*}>0$. This implies $\lambda_{x} \geq 0$ and $\lambda_{z}=\lambda_{y}=0$. Using the first-order conditions we find that

$$
\lambda_{x}=\frac{1}{r}(r-t)
$$

We see that $\lambda_{x} \geq 0$ iff $r \geq t$. Thus, zero effort by the firm is part of a Nash equilibrium only if the union values the prize at least as much as the firm.

2) Assume that $z^{*}=0$, whereas $x^{*}>0$ and $y^{*}>0$. This implies $\lambda_{z} \geq 0$ and $\lambda_{x}=\lambda_{y}=0$. Again, using the first-order conditions we have that

$$
\lambda_{z}=\frac{1}{t}(t-r)
$$

From (A.11) it is apparent that $\lambda_{z} \geq 0$ iff $t \geq r$.

If valuations are equal, i.e. $r=t$, we know from the first part of the proof that $x^{*}=0$ or $z^{*}=0$ are parts of only two of a multiplicity of equilibria. In this case there is a continuum of Nash equilibria in which the firm plays $x^{*}=b \in\left[0, \frac{t^{2}(2 t+h)}{(3 t+h)^{2}}\right]$ and the union plays $z^{*}=\left(\frac{t^{2}(2 t+h)}{(3 t+h)^{2}}-b\right)$.

From (A.10) and (A.11) we see that $x^{*}=0$ is part of a unique Nash equilibrium if the union has a strictly higher valuation, i.e. $r>t$, whereas $z^{*}=0$ is part of a unique equilibrium if the firm has a strictly higher valuation of the prize, i.e. $t>r$. 


\section{B. Wage bargaining with linear demand}

Assuming labour to be the only input factor, the production function is given by

$$
q=l
$$

where $q$ is the quantity produced, and $l$ is the amount of labour employed by the firm. The inverse demand function is given by

$$
p=1-q
$$

The negotiated wage is given by the outcome of an asymmetric Nash bargaining model, i.e. ${ }^{12}$

$$
w=\arg \max _{w}[w l(w)]^{\alpha}[(1-l(w)-w) l(w)]^{1-\alpha}
$$

where $\alpha$ is interpreted as the relative bargaining strength of the union. The labour demand function, $l(w)$, is determined by the firm's profit maximising behaviour.

With these assumptions, the equilibrium levels of wage and output are easily calculated:

$$
\begin{gathered}
w=\frac{1}{2} \alpha \\
q=l=\frac{1}{2}-\frac{1}{4} \alpha
\end{gathered}
$$

With the above values of $w$ and $q$, simple calculation yields

$$
\begin{aligned}
& t=\frac{1}{16}(2-\alpha)^{2} \\
& r=\frac{1}{8} \alpha(2-\alpha) \\
& h=\frac{1}{32}(2+\alpha)^{2} \\
& c s=\frac{1}{32}(2-\alpha)^{2}
\end{aligned}
$$

\footnotetext{
12 For simplicity, the disagreement points are set equal to zero.
} 


\section{References}

Bergstrom, T.C., Blume, L., Varian, H. (1986) On the private provision of public goods. Journal of Public Economics 29, 25-49

Chamberlin, J. (1976) A diagrammatic exposition of the logic of collective action. Public Choice 26, 59-74

Christophides, L., Oswald, A. (1992) Real wage determination and rent-sharing in collective bargaining agreements. Quarterly Journal of Economics 107, 985-1002

Cornes, R., Sandler, T. (1985) The simple analytics of pure public good provision. Economica 52, $103-116$

Dixit, A. (1987) Strategic behavior in contests. American Economic Review 77, 891-898

Ellingsen, T. (1991) Strategic buyers and the social cost of monopoly. American Economic Review $81,648-657$

Fabella, R. (1993) Consumer resistance and monopoly behavior under contestability. Public Choice $76,263-271$

Fabella, R. (1995) The social cost of rent seeking under countervailing opposition to distortionary transfers. Journal of Public Economics 57, 235-247

Katz, E., Nitzan, S., Rosenberg, J. (1990) Rent-seeking for pure public goods. Public Choice 65, 49-60

Krueger, A.O. (1974) The political economy of the rent-seeking society. American Economic Review 91, 291-303

Lee, S. (1995) Endogenous sharing rules in collective-group rent-seeking. Public Choice 85: 33-44

McGuire, M.C. (1974) Group size, group homogeneity, and the aggregate provision of a pure public good under Cournot behavior. Public Choice 18, 107-126

Nitzan, S. (1991) Collective rent dissipation. Economic Journal 101, 1522-1534

Nitzan, S. (1994) Modelling rent-seeking contests. European Journal of Political Economy 10, 41-60

Olson, M. (1965) The logic of collective action. Harvard University Press, Cambridge

Oswald, A. (1985) The economic theory of trade unions: An introductory survey. Scandinavian Journal of Economics 87, 160-193

Posner, P.A. (1975) The social cost of monopoly and regulation. Journal of Political Economy 83, 807-827

Rama, M. (1997) Imperfect rent dissipation with unionized labor. Public Choice 93, 55-75

Rose, N.L. (1987) Labor rent sharing and regulation: Evidence from the trucking industry. Journal of Political Economy 95, 1146-1178

Skaperdas, S. (1996) Contest success functions. Economic Theory 7, 283-290

Tullock, G. (1967) The welfare costs of tariffs, monopolies, and theft. Western Economic Journal 5, 224-232

Tullock, G. (1980) Efficient rent-seeking. In: Buchanan, J., Tollison, R., Tullock, G. (eds.) Towards a theory of the rent-seeking society. Texas A\&M University Press, College Station 